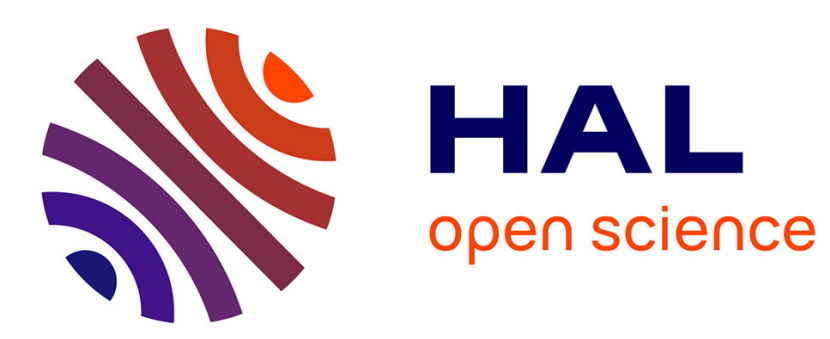

\title{
On the Bullet-Streamer Dualism
}

S. Reuter, A. Schmidt-Bleker, S. Iseni, Joern Winter, K. Weltmann

\section{To cite this version:}

S. Reuter, A. Schmidt-Bleker, S. Iseni, Joern Winter, K. Weltmann. On the Bullet-Streamer Dualism. IEEE Transactions on Plasma Science, 2014, 42 (10), pp.2428-2429. 10.1109/TPS.2014.2332539 . hal-02270237

\section{HAL Id: hal-02270237 \\ https://hal.science/hal-02270237}

Submitted on 28 Jun 2021

HAL is a multi-disciplinary open access archive for the deposit and dissemination of scientific research documents, whether they are published or not. The documents may come from teaching and research institutions in France or abroad, or from public or private research centers.
L'archive ouverte pluridisciplinaire HAL, est destinée au dépôt et à la diffusion de documents scientifiques de niveau recherche, publiés ou non, émanant des établissements d'enseignement et de recherche français ou étrangers, des laboratoires publics ou privés. 


\title{
On the Bullet-Streamer Dualism
}

\author{
Stephan Reuter, Ansgar Schmidt-Bleker, Sylvain Iseni, Jörn Winter, and Klaus-Dieter Weltmann
}

\begin{abstract}
Formerly so-called bullet jets have been in the focus of atmospheric pressure plasma jet research of the past years. In this paper, two perspectives of the dynamic phenomenon are presented. Averaged, the dynamics appears as a bright spot-the so-called bullet-traveling from the plasma jet nozzle. In single shot it is revealed that the discharge mode in fact is a streamertype discharge leaving the jet nozzle into the ambient.
\end{abstract}

Index Terms-Atmospheric-pressure plasmas, fluorescence, plasma diagnostics.

\section{INTRODUCTION}

$\mathbf{S}$ O-CALLED plasma bullet jets exhibit bright dynamic features appearing as bright spots traveling from the plasma jet nozzle into the ambient surrounding [1]. These cold plasma jets are typically in the millimeter scale. A typical field of application of these jets is plasma medicine. Several works have already shown that the bullet is connected to the nozzle by a tail like structure [2] and can be snake like [3]. Usually, these jets are operated in pulsed or $\mathrm{kHz}$ mode [4], [5]. Recently, these features have been observed also in a plasma jet operated at $\sim 1 \mathrm{MHz}[6]$.

In this paper, a plasma jet, the so-called kinpen [7], developed by the INP Greifswald is investigated. It is operated within a turbulent flow regime at three standard liter per minute of argon with no admixture in open air. For the singleshot images, over only one excitation period, a CCD camera (Imager Pro X, LaVision GmbH, Germany) combined with an external gated image intensifier is used with a gate width of $5 \mathrm{~ns}$. It has a high sensitivity and can thus detect single shot images of the discharges effluent. For the bullet images, phase resolved optical emission imaging is used [ibid.]. For these measurements, an intensified CCD-camera (Picostar, LaVision $\mathrm{GmbH}$, Germany) is triggered repetitively at the same point of phase in the duty cycle of the excitation frequency of the plasma. An averaged image ( $>200000$ excitation period) is recorded at a fixed gate width of $1 \mathrm{~ns}$ acquired at each excitation period. Subsequently, the trigger point is shifted toward a later point in the duty cycle phase and the process is

Manuscript received November 1, 2013; revised May 16, 2014; accepted June 14, 2014. Date of publication July 28, 2014; date of current version October 21, 2014. This work was supported by the Federal German Ministry of Education and Research under Grant 03Z2DN12.

S. Reuter, A. Schmidt-Bleker, S. Iseni, and J. Winter are with the Center for Innovation Competence Plasmatis, INP Greifswald, Greifswald 17489, Germany (e-mail: stephan.reuter@inp-greifswald.de; ansgar.schmidtbleker@inp-greifswald.de; sylvain.iseni@inp-greifswald.de; winter@inpgreifswald.de).

K.-D. Weltmann is with the Leibniz Institute for Plasma Science and Technology, INP Greifswald e.V., Greifswald 17489, Germany (e-mail: weltmann@inp-greifswald.de).

Digital Object Identifier 10.1109/TPS.2014.2332539 repeated. The result is a time-averaged movie of the emission pattern during a whole duty cycle (or longer). If the plasma jet exhibits the bullet characteristics, these bullets appear as a moving emission packet in the effluent with speeds of up to several $10.000 \mathrm{~m} / \mathrm{s}$. It is now agreed that the bullets rather are streamers and ionization fronts. In the following, it is shown that the observation of this bullet behavior depends on the measurement technique used.

From this paper, it is clarified that the appearance of the plasma jet is due to the way it is measured. At short exposure times of a few nanoseconds, the ionization front becomes visible [see Fig. 1(a) and (b)]. Acquisition of only one excitation period exhibits the streamer-like nature of the discharge [Fig. 1(a)] with a tail connecting the streamer head to the nozzle, as has been observed for other plasma sources [8]. The head has a much stronger intensity. The streamer path follows a nonregular pattern, which can be attributed to the path of purest argon, determined by impurity diffusion, as previous investigations have shown [9]. Averaging over many periods of excitation, but fixing the exposure gate to one phase point exhibits a feature, which had been described as a plasma bullet. Here, the varying streamer path results in a weaker emission connected to the nozzle [Fig. 1(b)].

Taking longer exposure gates over the whole period will reveal the complete streamer pathway [Fig. 1(c)].

Averaging over many periods will show the plasma jet as seen by the naked eye in a flame-like appearance [Fig. 1(d)].

From the investigations, it can be seen that the bullet pattern observed by PROES measurements is a result from the averaging procedure. The streamer head [in Fig. 1(a)] results in the bullet feature observed in Fig. 1(b) when averaged over a large number of periods (due to technical reasons, the phase point is not exactly the same for both measurements).

On the timescale of the bullet propagation, the vortices in the flow field appear stationary and the discharge follows the winding argon channel as revealed by the single shot measurements. Averaging over many periods at the same phase position yields a smoothed emission pattern.

Concluding, it can be remarked that the investigated plasma jet can appear either as a bullet jet, if imaging is averaged over a larger number of periods or as a streamer discharge if observed in single shot mode. This is the bullet-streamer dualism in the atmospheric pressure plasma jet. For modeling and for diagnostics as well as for the application field, these different appearances have to be known and taken into account. 


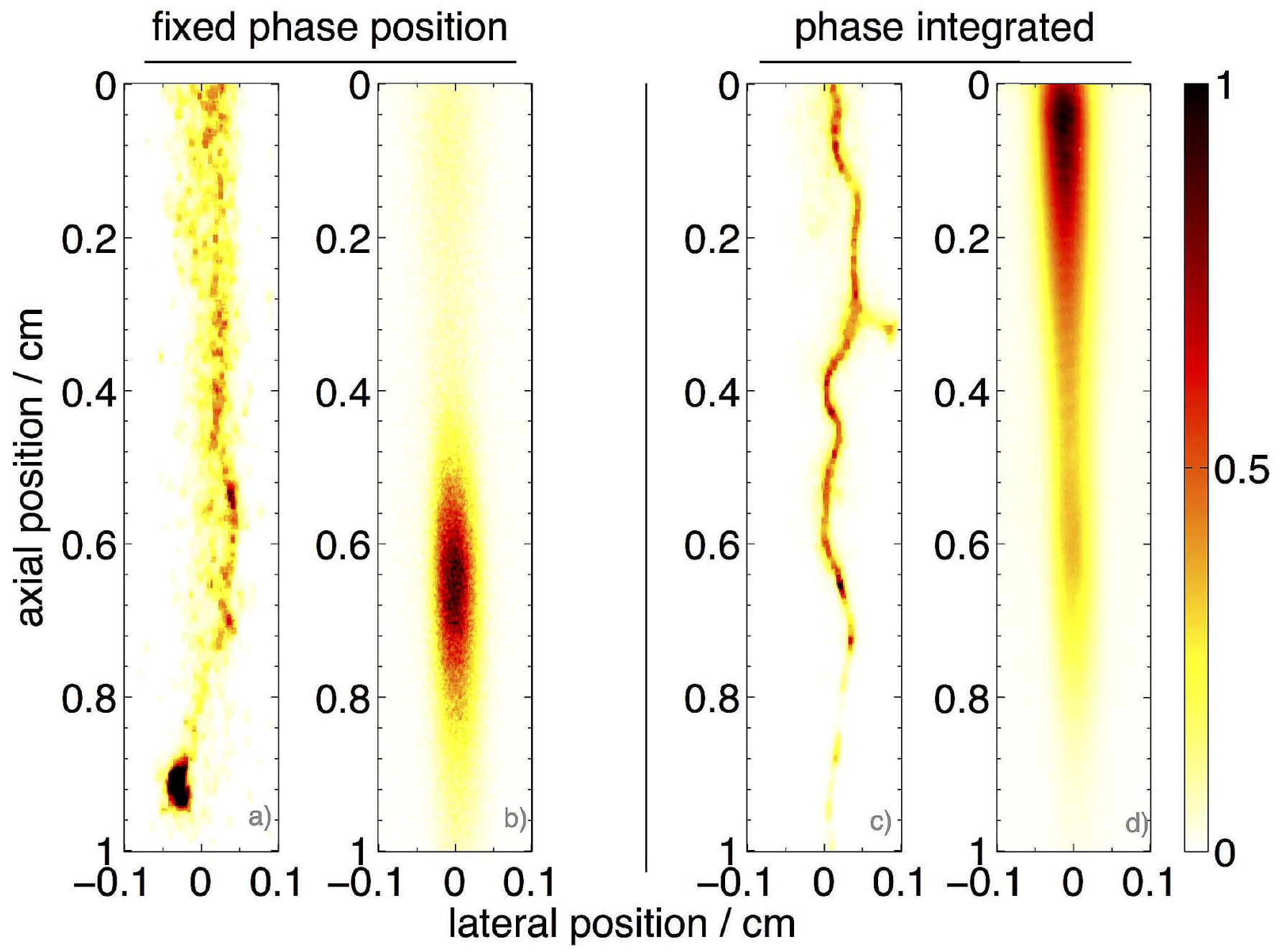

Fig. 1. Contrasted perspectives of the effluent of an atmospheric pressure argon plasma jet. The intensity scale is given in relative units. The lateral scales range from -0.1 to $0.1 \mathrm{~cm}$ for each data set. (a) and (c) taken over one excitation period with a gate width of (a) $5 \mathrm{~ns}$ and (c) over the whole period. (b) and (d) taken over many excitation periods (>200000) with a gate width of (b) 1 ns and (d) over a whole period. While (a) and (c) show the wavelength integrated emission of the jet, an optical filter imaging the argon emission at $706.7 \mathrm{~nm}$ was used in (b) and (d) in order to cut the emission from long-living excited species.

\section{REFERENCES}

[1] M. Laroussi, W. Hynes, T. Akan, X. P. Lu, and C. Tendero, “The plasma pencil: A source of hypersonic cold plasma bullets for biomedical applications," IEEE Trans. Plasma Sci., vol. 36, no. 4, pp. 1298-1299, Aug. 2008.

[2] J. Jarrige, M. Laroussi, and E. Karakas, "Formation and dynamics of plasma bullets in a non-thermal plasma jet: Influence of the high-voltage parameters on the plume characteristics," Plasma Sources Sci. Technol., vol. 19 , no. 6 , p. $065005,2010$.

[3] X. Lu, G. V. Naidis, M. Laroussi, and K. Ostrikov, "Guided ionization waves: Theory and experiments," Phys. Rep., vol. 540, no. 3, pp. 123-166, 2014.

[4] X. Lu, M. Laroussi, and V. Puech, "On atmospheric-pressure nonequilibrium plasma jets and plasma bullets," Plasma Sources Sci. Technol., vol. 21, no. 3, p. 034005, 2012.

[5] X. Lu and M. Laroussi, "Dynamics of an atmospheric pressure plasma plume generated by submicrosecond voltage pulses," J. Appl. Phys., vol. 100, no. 6, p. 063302, 2006.
[6] S. Reuter, J. Winter, S. Iseni, S. Peters, A. Schmidt-Bleker, M. Dünnbier, J. Schäfer, R. Foest, and K.-D. Weltmann," "Detection of ozone in a MHz argon plasma bullet jet," Plasma Sources Sci. Technol., vol. 21, no. 3, p. $034015,2012$.

[7] K.-D. Weltmann, E. Kindel, R. Brandenburg, C. Meyer, R. Bussiahn, C. Wilke, and T. von Woedtke, "Atmospheric pressure plasma jet for medical therapy: Plasma parameters and risk estimation," Contribut. Plasma Phys., vol. 49, no. 9, pp. 631-640, 2009.

[8] E. Robert, V. Sarron, D. Ries, S. Dozias, M. Vandamme, and J. M. Pouvesle, "Characterization of pulsed atmospheric-pressure plasma streams (PAPS) generated by a plasma gun," Plasma Sources Sci. Technol., vol. 21, no. 3, p. 034017, 2012.

[9] S. Iseni, A. Schmidt-Bleker, J. Winter, K. D. Weltmann, and S. Reuter, "Atmospheric pressure streamer follows the turbulent argon air boundary in a $\mathrm{MHz}$ argon plasma jet investigated by $\mathrm{OH}$-tracer PLIF spectroscopy," J. Phys. D, Appl. Phys., vol. 47, no. 15, p. 152001, 2014. 